\title{
Environmental Risks: Doing Business In China
}

Jack Ethridge, Stephen F. Austin State University, USA

Treba Marsh, Stephen F. Austin State University, USA

Esther Bunn, Stephen F. Austin State University, USA

\begin{abstract}
Planning and conducting the audit of financial statements involves understanding the entity and the environment in which it operates. First and foremost this requires identifying the risks faced by the entity. Identifying these risks can be a complex and difficult task since the auditor needs to not only understand the entity's risk process but also independently understand the risks facing the firm. Tackling this task will involve a comprehensive review of the external and internal factors affecting the business. It is possible many identified business risks are related to financial reporting risk and ultimately to audit risk. Therefore, the auditor must understand the linkage between risks, controls and the audit. The objective of this paper is to examine the risks faced by U.S. companies conducting business in China. This paper attempts to identify a wide array of risks faced by U.S. companies to demonstrate how important it is for the company and the auditor to understand the business environment.
\end{abstract}

Keywords: Auditing; Entity Risks; International Operations; Controls

\section{BACKGROUND}

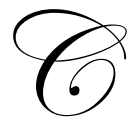

hina is the fastest-growing market on the planet, boasting 1.3 billion potential customers and annually quadrupling per capita income. China has an insatiable appetite for merchandise and services such as energy, chemicals, machinery, telecommunications, medical equipment, construction, services and franchising. It is the manufacturing center of Asia. As a recent World Trade Organization (WTO) member, China now permits its local companies to operate globally and foreign firms to compete with Chinese enterprises. However, it appears U.S. companies will face greater competition in China because the Chinese government supports its own companies and more Western companies are entering the Chinese market. However, China's prospects are matched by its perils (Alexander, 2001).

\section{MACRO RISKS}

\section{Demographic Environment}

The main demographic force that marketers monitor is population since people comprise markets. The population explosion in China has been a source of major concerns; however, the growing population does not mean growing markets unless these markets have sufficient purchasing power. In addition, the population distribution by age and gender can affect purchasing power and merchandise categories. Usually, a population can be subdivided into six age groups: preschool, school-age children, teens, young adults age 25 to 40 , middle-aged adults age 40 to 65 , and older adults age 65 and up. The most populous age groups shape the marketing environment. Graph 1 shows the China population pyramid for 2010 (NationMaster).

Teenagers are a significant consumer group in China, but they cannot afford what they like and want. Thus, teens are users and their parents are buyers. In this situation, the company must consider consumer psychology of both teens and middle-age groups. Teens prefer new types of goods which they have never seen or used before and popular goods which make them appear fashionable. However, if the good is too avant-garde or expensive, parents 
will either not accept it or cannot afford it resulting in the good not being purchased. Therefore, age distribution is one of the risks that American companies face in China.

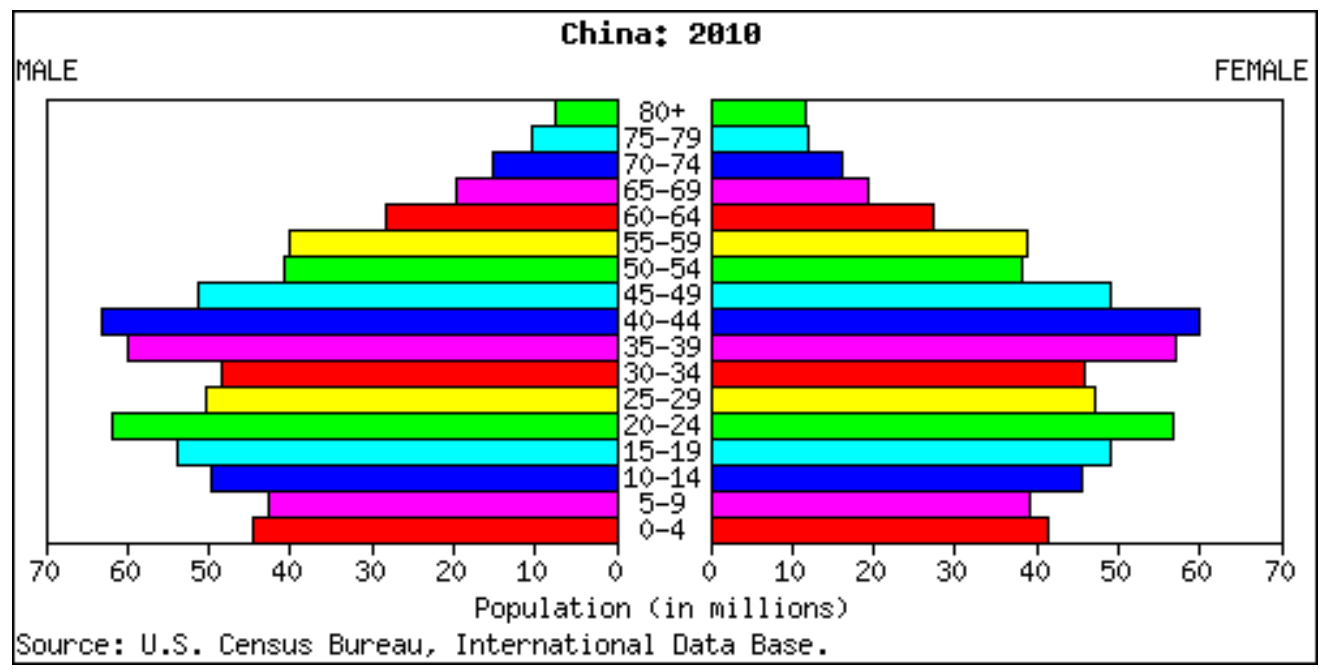

Graph 1

Location makes a difference in goods and service preferences. In China, people who live in large cities like luxury goods and service while those in smaller cities tend to spend money on cheaper goods and essentials. The location of people dictates whether the company's target consumers have both purchasing power and desire. Therefore, risks exist if American companies do not recognize the income differences between urban and rural areas and analyze their different preferences.

The culture or the instability of a country may create risks that make it difficult for multinational companies to operate safely, effectively, and efficiently. There are seven major Chinese dialects and many sub-dialects. Mandarin, the predominant dialect, is spoken by over 70 percent of the population. It is taught in all schools and is the medium of government. About two-thirds of the Chinese people are native speakers of Mandarin; the rest, concentrated in southwest and southeast China, speak one of six other major Chinese dialects. Non-Chinese languages spoken widely by ethnic minorities include Mongolian, Tibetan, Uyghur, other Turkic languages and Korean (U.S. Department of State). American companies must learn multiple dialects to be successful in the Chinese market.

Even in Mandarin dominant areas some translation problems are still a concern. For example, when CocaCola Company entered into the Chinese market, the company translated the name as "keken-kela" which means "it can bite and it is spicy." Obviously, Chinese consumers were confused. As Coca-Cola learned more about Chinese languages the name was translated to "kekou-kele" which means "delicious and joy."

American companies considering doing business in China should follow local customs and beware of cultural taboos. Chinese people value friendships with clients and ask questions about family, hobbies or daily life. Often Chinese people invite clients to restaurants or places of entertainment to express their sincerity. However, Americans may feel this is a waste of time because these activities have nothing to do with business. If American business representatives show their impatience or lack of enjoyment, Chinese people believe the American company does not want to do business with them and the opportunity will be lost.

\section{Politics and Laws}

Business decisions are strongly affected by developments in the political and legal environment. Political actions and instability make it difficult for companies to operate efficiently in China due to negative policies created 
by individuals in top government. A firm cannot effectively operate to its full capacity to maximize profits in an unstable political environment. In all important government, economic and cultural institutions in China, the Communist Party Committees work to ensure party and state policy guidance is followed and that non-party members do not create autonomous organizations that could challenge party rule. Party control is strongest in government offices and in urban economic, industrial and cultural settings. Thus, if an American company wants to do business in China, it has to pass scrutiny and obtain a permit from the government. Since many rules for multinational companies are strict and complex, it is easy to be refused entrance into the China market.

The relationship between U.S. and China also affects American companies. For example, President Obama's decisions to restrict imports and exports to China to protect the American economy made many influential Chinese enterprises angry. Some organized a union refusing to trade with any American companies resulting in many American companies giving up part of the Chinese market and/or changing their markets to Southeast Asia.

There are other risks due to the political relationships between America and other countries which may affect trade between China and the U.S. China plans to unify Taiwan. After recent news reports that some American companies sold military weapons to the Taiwan government, the Chinese government took actions against the American companies. In addition, many Chinese people refuse to buy American products because they believe the U.S. government is against the unification of China Taiwan.

From the perspective of laws and regulations, China usually requires many specific implementation rules and measures. However, vagueness allows Chinese courts and officials to apply them flexibly resulting in inconsistencies. Companies often have difficulty determining precisely whether or not their activities comply with or contradict a particular regulation. Agencies at all levels of government have rulemaking authority, resulting in regulations that are frequently contradictory despite China's commitment to ensure that these measures conform to its WTO obligations. While there seems to be no shortage of rules and regulations, there are few procedures in place to appeal regulatory decisions.

Intellectual property protection in China is very weak compared to North America. Since joining the WTO, China has strengthened its legal framework and amended its Intellectual Property Regulation (IPR) and related laws and regulations to comply with the WTO Agreement on Trade-Related Aspects of Intellectual Property Rights (TRIPs). However, despite stronger statutory protection, China continues to be a haven for counterfeiters and pirates. According to one copyright industry association, the piracy rate remains one of the highest in the world and U.S. companies lose over one billion dollars in legitimate business each year to piracy. On average, 20 percent of all consumer products in the Chinese market are counterfeit (Export.gov). If a product sells, it is likely to be illegally duplicated which creates additional problems. Customers may not be differentiating between the real and counterfeit products, resulting in a perception of low quality. Undoubtedly, the pirates or counterfeiters not only cause loss of money, but also damage the enterprise or brand image. Thus, American companies need to be more diligent in protecting their own intellectual property rights. Although there is a commitment on the part of many central government officials to tackle the problem, enforcement measures to date have not been sufficient to effectively deter massive IPR infringements.

Though China's economy has expanded rapidly, its regulatory environment has not kept pace. Since Deng Xiaoping's open market reforms, the growth of new business has outpaced the government's ability to regulate them. This has created a situation in which businesses faced with mounting competition and poor oversight will take drastic measures to increase profit margins, often at the expense of consumer safety (U. S. Department of State).

\section{Economy}

Markets require purchasing power. Unfortunately, extreme disparity exists between the rich and the poor in China. The available purchasing power in an economy depends on current income, prices, savings, debt, and credit availability. Marketers monitor trends affecting purchasing power because they can have a strong impact on business, especially for companies whose products are geared to high-income or price-sensitive consumers. 
Annualized consumer price index (CPI) is at an uncomfortable level. There are several reasons for the rapidly rising prices in China. Chinese currency's appreciation has only a limited impact on the rising price of commodity imports. The rising food and metals prices in the world have directly contributed upward pressure to China's CPI. The rising energy prices globally are creating difficulties on Chinese government's domestic price control measures. The ability of downstream industries to absorb price pressures from upstream materials suppliers has become minimal.

Price controls are hard to maintain. The government's price control measures can certainly be effective to keep down price hikes in the short term, but it has been proven that the "control - subsidy" mechanism may not be sustainable (Zhang).

\section{Trade Risks}

While China has an increasingly open and competitive economy, substantial barriers have yet to be dismantled. Import barriers, an opaque and inconsistent legal system, and limitations on market access combine to make it difficult for American firms to operate in China. Business interests must be realistic about the impact of WTO accession. It has brought, and will continue to bring, enormous changes - both economically and socially but WTO entry will not remove all commercial problems and the implementation process will take time.

The Minister of Commerce established the Catalogue for Goods Subject to Import Licensing. Three categories of products require import licenses: raw materials for chemical military weapons, toxicant or drugs, and ozone depleting materials. Products subject to import quotas also require import licenses, including some wool, grains, oilseeds, oilseed products, and cotton. China has also added license requirements to some products in an effort to combat smuggling. Import licenses are not always easy to obtain because the Chinese government must verify the qualification of imported goods causing long delays.

China's service sector has been one of the most heavily regulated and protected parts of the national economy. Many of the regulations implementing these commitments have imposed excessively high capital requirements and geographical and other limitations on expansion that appear intended to limit market access.

\section{MICRO RISKS}

\section{Accounting, Tax, and Financial Risk}

If a company plans to borrow from Chinese banks, the banks check and audit the company's background. Usually, banks require a company to show a profit in the last few years. Banks grade the company, including the company's credit level, investment level, profit level and determine the amount of money to loan. High pollution industries and high energy use industries are not allowed to borrow from Chinese banks (Zhang).

China's tax rules are often a major hurdle for foreign enterprises. The tax laws are written in Chinese with vast differences in tax treatment, filing, and payment procedures based on the business activity and location of business. Chinese tax authorities are strengthening the controls in tax enforcement and collection policies. Independent tax audit and investigation teams at different levels of the tax bureaus have been increasing their efforts to curb tax evasions. The tax system in China is complicated with the different types of taxes involved and local interpretations which may create various "tax traps" for foreign investors. With the issuance of the revised Tax Administration and Collection Law, tax authorities were granted more authority to access taxpayers' information and strengthen the tax collection measures (Ngai).

\section{Product and Service}

Companies must consider the widely varying tastes in China. Regardless of the good or service, it is very important to choose a proper entrance strategy. There are three different strategies, including straight extension, product adaptation and product invention. Straight extension means introducing the product in the foreign market without change. This strategy costs less than the other two, but the risk is higher since the Chinese people may not 
accept or like it. The second strategy, product adaptation, involves altering the goods to meet local conditions or preferences. Products are easier for consumers to accept; however, it costs money to change the products for Chinese consumers. Additionally, the company needs to consider the competition from Chinese enterprises and other foreign enterprises. If the revenue cannot cover the cost or the altered product is not superior to that of competitors, the company not only loses money but also market shares. Product invention consists of creating something new. This strategy introduces new products to the Chinese market which can trigger consumers' curiosity and purchase of the new goods. However, there is the risk that those goods will not be accepted. The risks include non-acceptance of the goods, high advertising costs, low market share, and few customers.

\section{Human Resource}

Top management should be either American or Chinese. Americans speak the language of the home office and understand their procedures which make reporting and operations easier. However, Americans often encounter problems because they do not understand Chinese culture and lack marketing experience in China. While these problems are often solved with Chinese top management, others are created. Chinese top management is often difficult to control and negotiate with due to distance, language and/or cultural barriers.

One of the greatest risks an organization faces is supervisors who are not trained in employment law and/or how to recruit and interview. Risks associated with the interview process include permitting untrained managers to ask illegal questions, requiring applicant tests that are invalid or illegal, and documenting inappropriate reasons for selection or non-selection. Supervisors should not ask applicants questions relating to their race, gender, religion, marital status, disabilities, ethnic background or country of origin (Vito, 2008). Any improper question(s) could be considered discrimination, often resulting in lawsuits.

Another area of concern for U.S. organizations is appropriately complying with the Labor Law of the People's Republic of China regarding overtime pay and the firing of employees. According to the Labor Law, an employer should pay triple daily salaries on holidays and double pay on weekends. In addition, if the company wanted to fire an employee, it should notify the employee one month in advance and pay unemployment compensation.

Due to economic pressure and greed, there is always the risk of employee fraud. For example, some enterprises agree to provide false invoices for their clients. Employees submit false invoices of business expenses to employers and pocket the overpaid amount. In addition, relationships are important in China, especially with government departments. If a government officer requests an employer to hire someone, it is understood the company will hire the individual even if he/she is not qualified for the position.

\section{SUMMARY}

The ultimate success or failure of any organization doing business in China or anywhere is dependent on how well the business and the auditor identifies and understands the risks facing the entity. As indicated, the business needs a well developed risk process. The auditor must understand both the organization's risk process and independently review the risks. This paper stresses that risks faced by an organization are many and complex and can come from external and internal sources. Eventually, the entity and the auditor must recognize that many identified risks have financial statement implications, and controls must be in place to mitigate those risks. The auditor must link this knowledge while conducting the audit.

\section{AUTHOR INFORMATION}

Jack R. Ethridge is the Temple-Inland Employees Distinguished Professor of Accounting in the Gerald W. Schlief School of Accountancy at Stephen F. Austin State University in Nacogdoches, TX. His areas of interest are auditing and financial.

Treba A. Marsh, professor, is the director of the Gerald W. Schlief School of Accountancy at Stephen F. Austin State University. Her areas of interest are governmental, financial and auditing. 
Esther S. Bunn is a lecturer in the Gerald W. Schlief School of Accountancy at Stephen F. Austin State University. Her areas of interest are financial, managerial and tax.

\section{REFERENCES}

1. Alexander, J. 2001. Doing Business in China Newsletter Reprint. Harvard Business Review, (March15) http:hbr.org/product/doing-business-in-china/an/CO103E-PDF-ENG?Ntt=doing+business+in+china

2. $\quad$ Export.gov. Protecting your Intellectual Propery Rights (IPR) in China. http://www.mac.doc.gov/China/Docs/businessguides/IntellectualPropertyRights.htm

3. Labour Law of the People's Republic of China. http://www.usmra.com/china/labour\%20law.htm

4. NationMaster. Chinese Population pyramids. http://www.nationmaster.com/country/ch/Age-distribution

5. Ngai, Jeremy. Managing Tax Risks of Doing Business in China. China Tax and Business Advisory Services. http://www.thechinaconnection.cn/articles/issue 005-4.pdf

6. U. S. Department of State. Background Note: China. http://www.state.gov/r/pa/ei/bgn/18902.htm\#people

7. Vito, Kelli. 2008. The Human Resources Audit: Adding HR to the Regular Audit Cycle Can Help Ensure Major Risks Aren't Overlooked. Internal Auditor 65.

8. Zhang, Face. Beware of Six Financial Risks in China http://ezinearticles.com/?Beware-of-Six-Financial$\underline{\text { Risks-in-China\&id=1223954 }}$ 